heat, it is further established by experiment that in this case the energy of motion does really persist as such. Thus a gas consists of molecules flying about with great velocity, rotating and vibrating, and so having energy of motion. All this energy of motion is what we call heat, and thus heat is a repetition of a known meaning of energy. Again, heat exists between a radiating body and the thing it warms; now the intermediate space is filled by the luminiferous ether, which, being elastic, has in its ultimate parts both energy of motion and energy of position. In these forms the heat exists in the space in question.

In the cases of heat and electricity the form of the persisting energy is pretty well ascertained. But there are cases in which we do not know if it is energy of motion or energy of position, such as that of chemical energv. In the burning of coal there is a falling together of carbon and oxygen [and heat is produced]; but we do not know in which of the two forms, if either, the energy which comes out as heat existed in the chemical process. For such a case the conservation of energy is only a probable statement (though of great probability) to the effect that in all cases where a physical quality is convertible with energy, that quality is itself either energy of motion or energy of position.

General Results.-Force is a quality of position, definite in magnitude and direction at any point ; not constant.

Energy is the name of two different quantities.

I. Energy of motion, half the rate at which a body carries momentum.

2. Energy of position, detined by the statement of the law that the work done in getting from one position to another is the same by whatever path the change of position is made.

[The definition of these conceptions helps to clear up sundry questions of mixed physics and metaphysics.]

I. Is a physical force, such as the attraction of the earth, analogous to our "exertion of force" in muscular work? No, for the sensation of muscular effort is very complicated. It involves nerre and muscle, which we know not to be present in the simpler cases, e.g., the motion of a stone let fall. To talk of pushing or pulling in such a case is a personification of external nature.

2. Are we directly conscious of force? It is often said in physical and metaphysical works that we are. It may be true, but it is at least premature. We do not knoze that the chemical changes in nerve-matter corresponding to consciousness are energy [only that they are convertible with dynamical energy]; much less do we know that they are force. If they are energy, it is energy of motion, not energy of position, since consciousness does not depend on the position of the nerve-matter [so my notes: sed quare].

3. Is mind a force? It is held by some that the will acts as the match to gunpowder, by setting loose a store of energy, the matter of the brain being in unstable equilibrium. But you cannot have in nature an absolutely unstable equilibrium [i.e., an equilibrium capable of being upset by an infinitesimal force], because the universe is not at rest [and every motion in the universe produces a finite change, however small, in the resultant force at every point of space]. Therefore if mind is force, operating in the way suggested, it must be able to create a determinate quantity of energy. This is a supposition which, if true, would destroy its own evidence; for it would destroy the uniformity of nature, on which all possibility of inference ultimately rests.

[The discourse concluded by pointing out that even from a purely scientific point of view, metaphysical speculation is to be encouraged as a spur to science.]

\section{ECHIS CARINATA}

THOSE who are interested in the poisonous snakes of India may have an opportunity of seeing one of the most interesting and destructive of these reptiles, now in the Zoological Society's Gardens in Regent's Park.

The snake I refer to is a fine specimen of the Echis carinata, which has recently arrived from India, and is the first of its kind, I am told, that has been received alive in this collection. I think it is probable, however, that a snake so common in some parts of India must have been brought alive to England before ; but at any rate it is rare, and sufficiently interesting to claim attention, especially as it is healthy, vigorous, and active, and readily shows its peculiar habits, in the attitude it assumes and the rustling sound it gives rise to by the friction of the carinated scales of one fold of its body against those of the other when alarmed, and in the aggressive position which it takes up when prepared to strike, which it does most viciously by launching out its head and the anterior part of its body from the centre of the convoluted folds into which it has arranged itself. There are, I believe, only two true vipers in India (though there are several Crotalidæ), the Daboia russellii, or chain viper, or ticpolonga, and the Echis carinata. The daboia is well known here, and there are, or have been lately, fine specimens in the Society's collection; but the echis is not so well known, though common enough in India.

It is much smaller than the Daboia, and is very active and dangerous. It is known in Sind as the "kuppur"; in other parts of the country as "phoorsa"; about Delhi it is "afäe," or "afai" (a word of Arabic origin). Russell calls it "horatta pam." It seldom attains more than the length of 20 to 22 or 23 inches; probably 15 or 16 inches is more common, and is from 2 to $2 \frac{1}{2}$ or 3 inches in circumference at the thickest part of the body.

It is very fierce and aggressive, always ready to attack. It throws itself into a double coil, the folds of which are in perpetual motion; the whole body does not necessarily change its place, and as they rub against each other they make a loud rustling sound, which may be mistaken for hissing. This is produced by the three or four outer rows of carinated scales, which are prominent and point downwards at a different angle to the rest; their friction against each other causes the loud rustling sound which gives notice of the presence of the echis, as does the rattle of the crotalus.

I have never heard this viper hiss; though the daboia does so loudly. It is of a brownish-grey colour, with white and dark spots, and a waying whitish band on either side of the body. On the head there is a peculiar mark something like a cross. Its fangs are very long and mobile, and its poison very active, destroying a fowl in two or three minutes. In Sind, and some other parts of India where it is very common, it causes considerable loss of human life, though I believe it is not so destructive on the whole as either the cobra or Bungarus ccruleus (Krait), which are more generally distributed over the peninsula. I have not seen it in Bengal, but it is common in the North-West Provinces, Punjab, Sind, and Central Provinces, and Southern India in the Carnatic, and about Madras.

Its aggressive aspect when roused, the vicious eye, its peculiar method of folding itself, the rustling of its scales, and the rapidity with which it strikes, make it, when living, an object of considerable interest.

In the same collection there is a fine specimen of another very rare colubrine venous snake, the Ophiophaous elaps, which gives an opportunity not often available even in India, where the snake is found only in certain localities, of studying its peculiar habits and food, which consists of other snakes. It is as deadly as the cobra, to which it is nearly allied; but from its comparative rarity and the nature of its habitat it does not contribute so largely to the death-rate as that snake or even as the little echis.

J. FAYRER 